\title{
Los pabellones vaticanos en las exposiciones internacionales
}

\author{
The Vatican Pavilions at International Exhibitions
}

José Ramón Alonso Pereira · Universidade da Coruña (España)

https://doi.org/10.17979/aarc.2013.3.0.5100

\section{RESUMEN}

El texto recorre la presencia de la Santa Sede en las distintas Exposiciones Internacionales, tanto de carácter universal como de carácter temático, desde la creación del Estado Vaticano en 1929 hasta nuestros días. Con estos pabellones, los distintos papas —desde Pío XI a Benedicto XVI_quisieron hacer presente a la Iglesia católica en los foros internacionales, entendiéndolos como actos de evangelización potencial frente al laicismo contemporáneo.

\section{ABSTRACT}

The text traces the presence of the Holy See in the different international exhibitions, both universal and thematic, from the creation of the Vatican State in 1929 until today. With these pavilions, the popes from Pius XI to Benedict XVI, wanted to represent the Catholic Church in international forums, understanding them as potential acts of evangelization against contemporary secularism.

\section{PALABRAS CLAVE}

Exposiciones internacionales; arquitectura efímera; arquitectura religiosa; Vaticano; Santa Sede.

\section{KEYWORDS}

International exhibitions; ephemeral architecture; religious architecture; Vatican; Holy See. 


\section{INTRODUCCIÓN}

En 1929, los Pactos de Letrán pusieron fin a la llamada «Cuestión Romana», planteada desde el final del proceso de la unificación italiana y la ocupación de Roma en 1870, consagrando la existencia de la Santa Sede como Estado de los tiempos modernos ${ }^{1}$. La Ciudad del Vaticano fue desde ese momento un sujeto jurídico internacional con capacidad, como tal, de participar en las Exposiciones Universales. La fuerte voluntad comunicativa y misionera del entonces papa Pío XI le animó casi de inmediato a aprovechar esos encuentros, entendiéndolos como actos de evangelización potencial frente al laicismo contemporáneo.

\section{LA EXPOSICIÓN UNIVERSAL DE PARÍS 1937}

Dejando aparte las exposiciones de Barcelona y Sevilla (1929) o las de Bruselas (1930/35) y Chicago (1933/34) — planteadas con anterioridad a los Pactos Lateranenses-, la primera oportunidad se presentó con la Exposición de París de 1937.

Programada ya en 1934, esta Exposición fue la mayor de las celebradas hasta entonces y quiso mostrar que no existía incompatibilidad entre lo bello y lo útil, el arte y la técnica, y que, si el progreso se desarrollaba bajo el signo del arte, ensanchaba los valores espirituales. Desarrollada del 24 de mayo al 26 de noviembre, en ella participaron cuarenta y cuatro países, que dieron una potente muestra de lo que estaba pasando en el mundo de la ciencia, la técnica y el arte del momento. Gestada en un clima de inestabilidad y agitación política, la Exposición fue una de las más completas, pero también una de las más controvertidas a causa de la conflictividad social, el auge de los sistemas totalitarios y la guerra civil española. De hecho, el pabellón de España actuó como un altavoz profético ${ }^{2}$.

Todos los pabellones foráneos pretendían mostrar la imagen de sus naciones respectivas, como se había realizado tradicionalmente desde el siglo XIX. Dentro de ellas, el pabellón vaticano — $\mathrm{O}$, como se dijo entonces, el «Pavillon Catholique Pontifical»— quiso mostrar en su estructura, decoración y alhajamiento el potencial que el hombre podía realizar con la ayuda de Dios (Fig. 01-03).

Erigido junto al Trocadero no lejos de los pabellones enfrentados de Rusia y de Alemania, y vecino al de la República Española, el pabellón simulaba un templo, con sus brazos, su ábside y su espacio central a modo

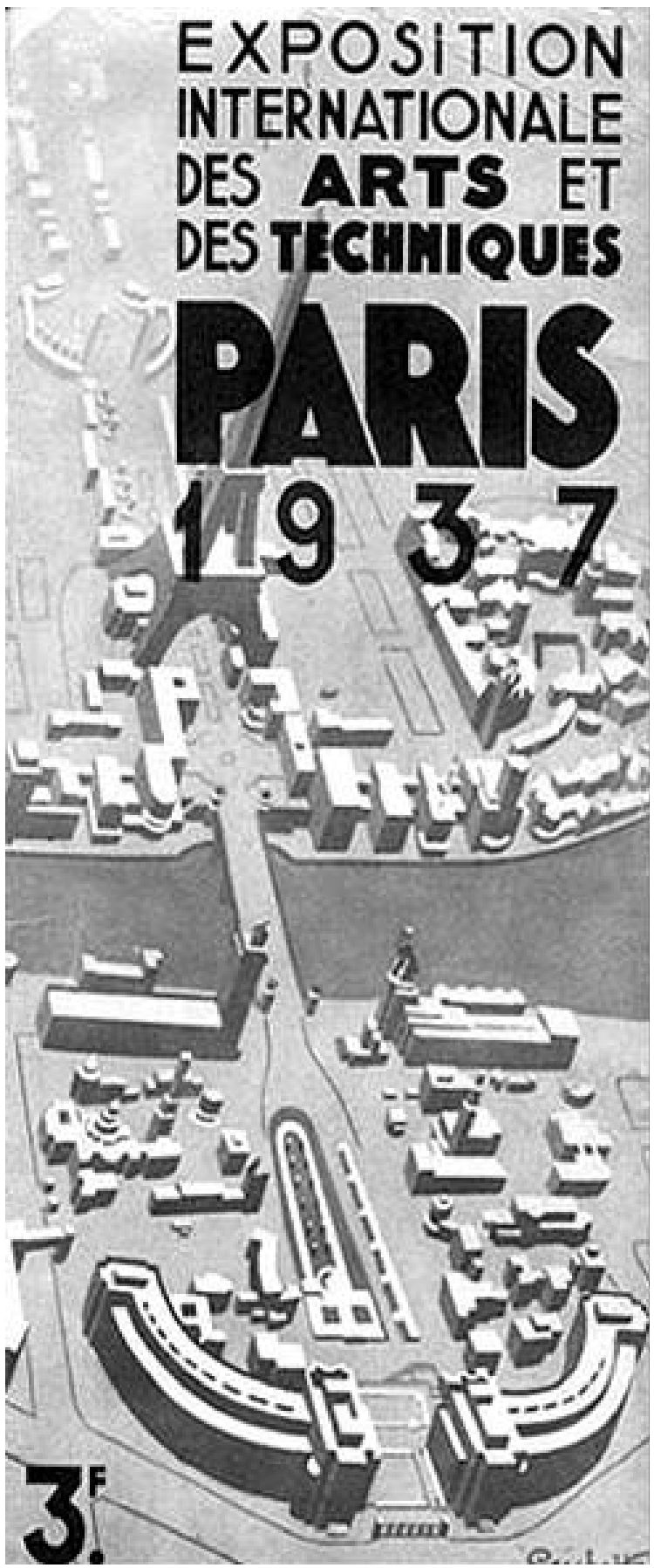

Fig. 01. La Exposición de París, 1937; imagen de conjunto. 


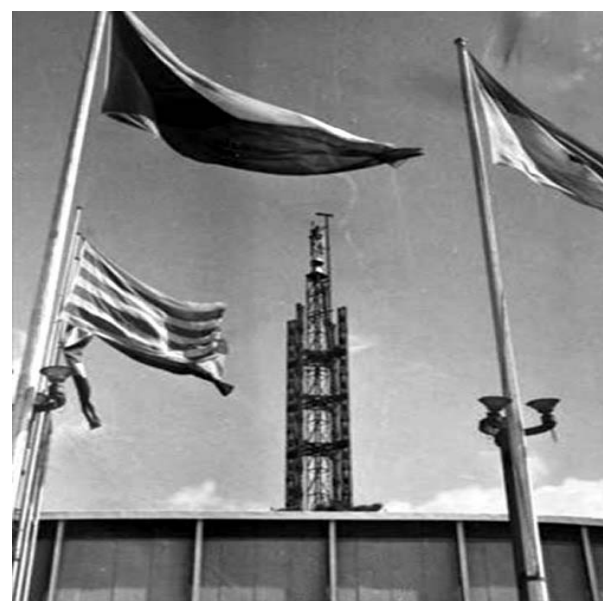

Fig. 02. Paul Tournon, pabellón de la Santa Sede en la Exposición de París 1937; torre y flecha metálica de

Raymond Subes. En primer plano, el pabellón de España.

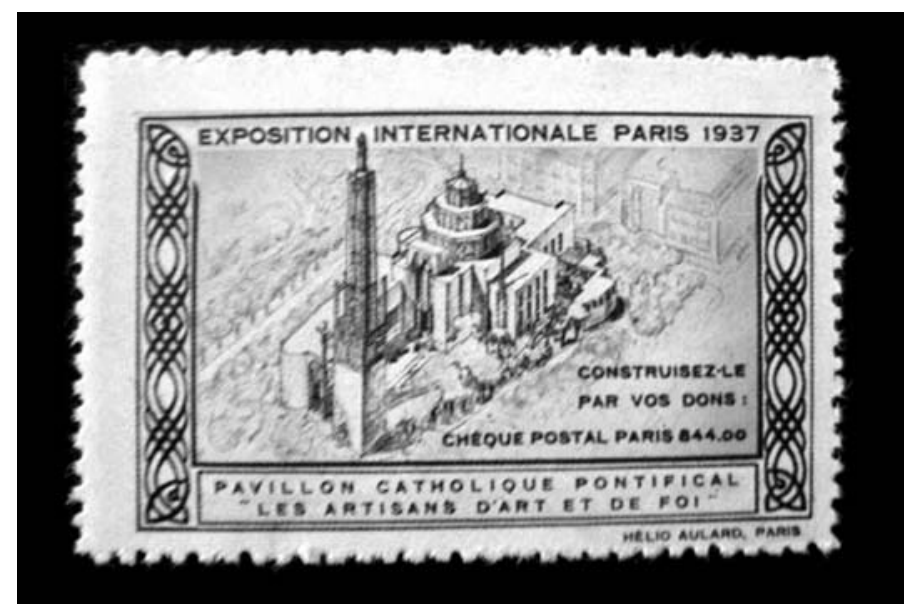

Fig. 03. Sello conmemorativo. de cimborrio octogonal, acompañado por un claustro y una alta torre ${ }^{3}$. Todo el pabellón representaba una visión próxima a los supuestos formales de la Exposición de 1925, con bases compositivas ligadas aún a los «elementos» de Julien Guadet.

Su arquitecto fue Paul Tournon (1881-1964) ${ }^{4}$, jefe de construcciones civiles y asesor del arzobispado de París, que contó con una colaboración múltiple de arquitectos, decoradores y artistas de diferentes naciones a las que se dirigió la Santa Sede con la intención expresa de dar un mensaje universal más abierto. Así, el baptisterio fue proyectado por el arquitecto Paul Flandrin y el claustro y el refectorio por Jean Guy, con un mural de la «Última Cena» de Maurice Denis. Había tres edículos con sendos altares: el de la Primera Comunión, obra de Froidevaux, con pintura y tapicería de Flandrin-Latron; un segundo altar con participación de los Países Bajos, proyecto del arquitecto Van Dillen y del interiorista y decorador Jos Ten Hornel; y un tercer altar, cedido al gobierno de Franco, obra de Jean Droz, al fondo del cual se situaba una monumental obra del gran muralista catalán José María Sert: «La Apoteosis de Santa Teresa», que simbolizaba la intervención de la santa en la guerra civil. Tournon se reservó el santuario o capilla del Buen Pastor, símbolo de la Santa Sede, coronado por la colosal imagen de NotreDame-de-France ${ }^{5}$, obra de Roger Villiers. Raymond
Subes realizó la cerrajería exterior e interior y la flecha metálica del pabellón. En todo caso, la obra de los artistas escogidos tuvo un impacto bastante discreto, en comparación con la admiración suscitada por los artistas del pabellón español.

En una época de luchas en Francia - como en España - entre la izquierda laica del Frente Popular, entonces en el poder, y la derecha católica, se insistió en la justificación estatal y no religiosa de la presencia vaticana, que quiso, tras la clausura, mantener en pie su edificio, reconvertido en pabellón mariano.

Esas luchas y esos contrastes se evidenciaban aún mejor en la presencia española ${ }^{6}$. Si el bando nacional tuvo su representación moral en el espacio cedido del Pabellón Vaticano, el pabellón de la República, proyectado por Luis Lacasa y José Luis Sert — sobrino del pintor y emblema con él de la división española-, exhibía obras de Renau, Miró, González, Alberto y, sobre todo, el «Guernica» de Picasso, símbolo de la Exposición.

A ese pabellón vaticano pionero iban a seguirle otros. Tras París, Estados Unidos celebró en 1939 dos muestras internacionales en San Francisco y en Nueva York, con lemas optimistas. Pero las tensiones internacionales oscurecieron el horizonte y limitaron la participación. 


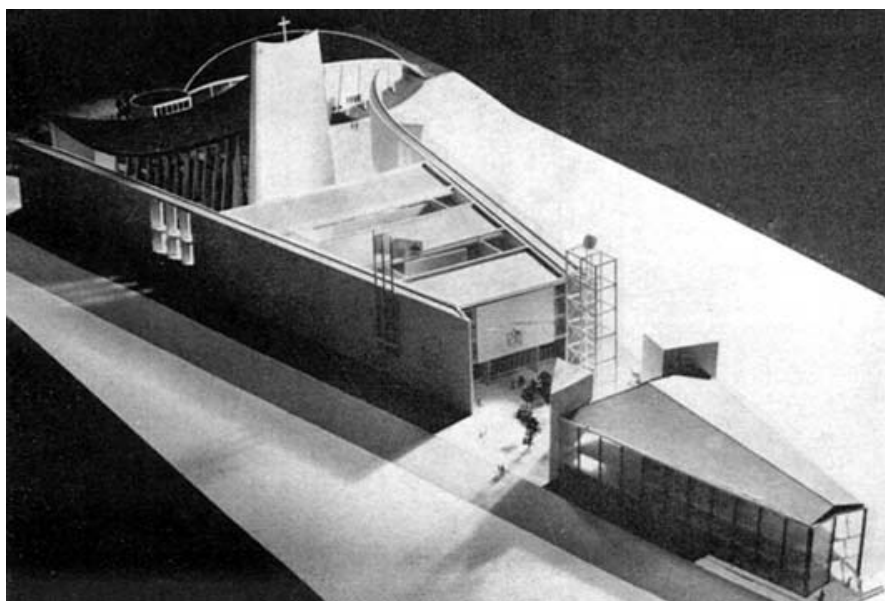

Fig. 04. Roger Bastin, «Civitas Dei», pabellón de la Santa Sede en la Exposición de Bruselas, 1958; maqueta.

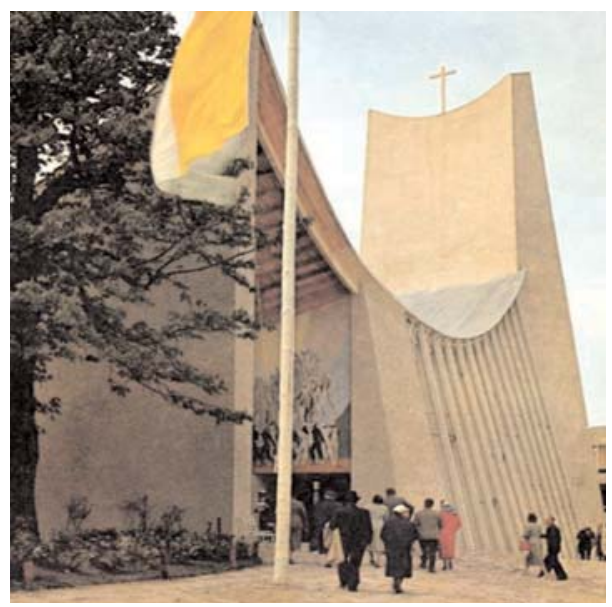

Fig. 05. Vista del pórtico de acceso.

\section{LA EXPO'58 DE BRUSELAS}

La Guerra Mundial y las reconstrucciones de la posguerra impidieron durante casi dos décadas la continuidad expositiva universal, que sólo se reanudó en 1958 en Bruselas, reflejo y corazón de la nueva Europa en construcción. Conocida popularmente como «la Exposición del Atomium», por ser ese su emblema, quiso reflejar el mundo moderno. Fue la exposición del «Poème Électronique» de Le Corbusier y del pabellón de los hexágonos español, de Corrales y Molezún. Pese a las tensiones de la «guerra fría», todos los países centraron sus esfuerzos en demostrar que los avances tecnológicos podían y debían ponerse al servicio de la paz y de un mundo más humano.

Sus ideales humanistas y de cooperación mundial atrajeron la atención de Pío XII, que quiso contribuir con un pabellón propio, explícitamente llamado «Civitas Dei», la Ciudad de Dios. El pabellón se organizó como un edificio de composición tripartita (Fig. 04-05). Fue su arquitecto Roger Bastin $(1913 / 86)^{8}-$ conocido como el «moderniste sage»—, que contó con la colaboración de su entonces socio Guy van Oost, aunque, como en París, se confió la ejecución de los aspectos sectoriales del pabellón a diversos autores ${ }^{9}$, reservándose Bastin la iglesia y su espadaña, cuyos cuarenta y un metros de altura la convirtieron en el edificio más alto de la Exposición. Proyecto de un interior radiante — se dijo-, contaba con capilla del Santísimo, auditorio, salas de exposiciones, restaurante, etc., llegando a celebrarse en ella representaciones, ceremonias e incluso bodas. El pabellón contaba con vitrales de Michel Martens y temas gráficos de Luc Verstraete. La capilla del Santísimo fue realizada por Pierre Pinsard (1906/88), arquitecto, pintor y decorador francés, miembro de la UAM (Unión de Artistas Modernos), autor asimismo del pabellón de Francia en la Exposición.

\section{LA NEW YORK WORLD'S FAIR, 1964/65}

A este pabellón seguirán otros bajo los pontificados de Juan XXIII y Pablo VI, en especial el presentado en la Exposición neoyorquina en 1964/65, que vio cómo la Piedad de Miguel Ángel viajaba a Nueva York, al tiempo que el Papa se dirigía desde allí al mundo en el foro de las Naciones Unidas.

Desarrollada durante dos años, en sendos periodos semestrales del 22 de abril de 1964 al 17 de octubre de 1965, la «World's Fair» fue la mayor exposición internacional desarrollada nunca. Dedicada a la paz y el entendimiento mundial, su símbolo fue una gran esfera metálica, imagen del globo terráqueo: la llamada «Unisphere». Aunque tuvo una presencia mayoritaria de pabellones comerciales y estuvo dominada por las corporaciones americanas, algunas presencias interna- 
Fig. 06. La «World's Fair» de Nueva York, 1964/65; imagen de conjunto, con el pabellón vaticano en primer término.

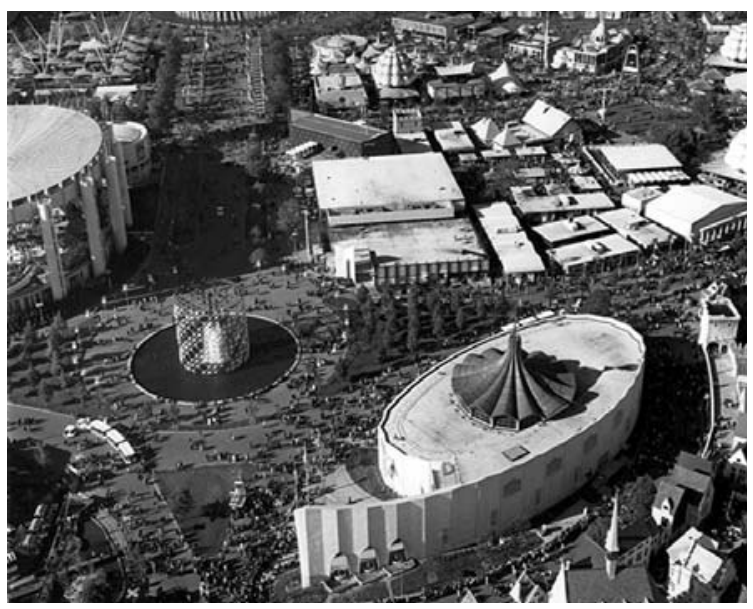

\section{VATICAN PAVILION CEREMONIES NEW YORK WORLD'S FAIR 1964-1965}
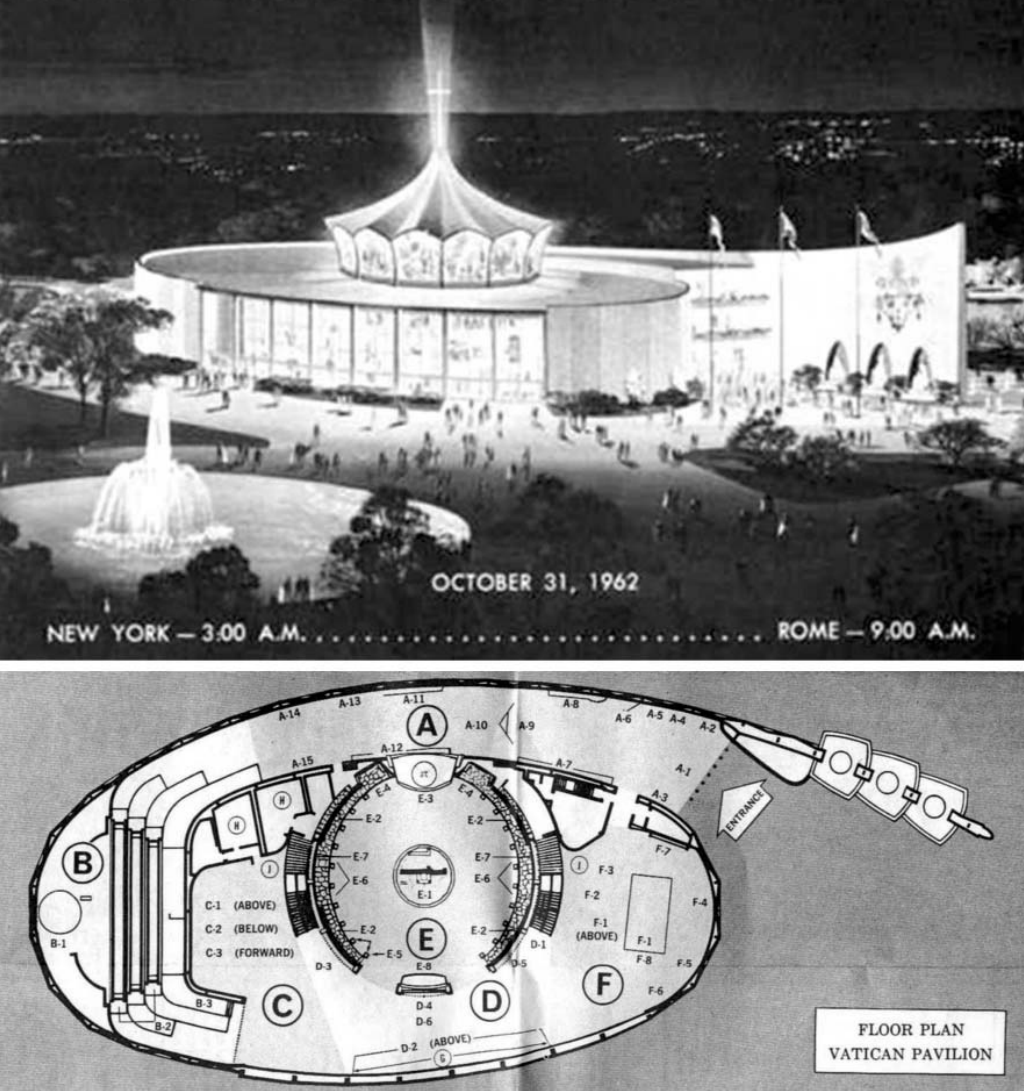

Fig. 07. York \& Sawyer, Hurley \& Hughes, y Luders \& Associates, pabellón de la Santa Sede en la Exposición de Nueva York, 1964/65; perspectiva y planta. 


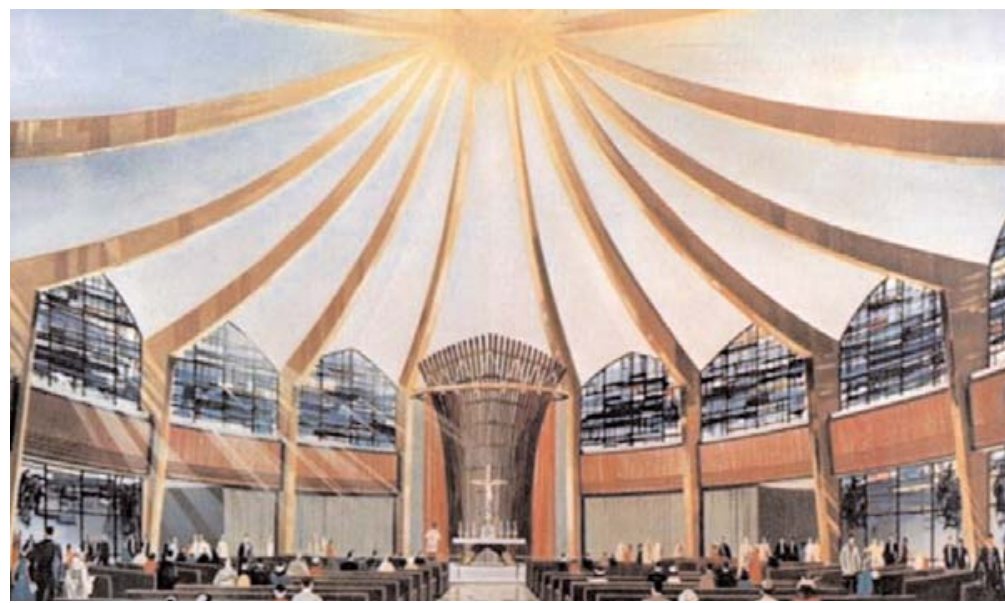

Fig. 08. York \& Sawyer, Hurley \& Hughes, y Luders \& Associates, pabellón de la Santa Sede en la Exposición de Nueva York, 1964/65; capilla.

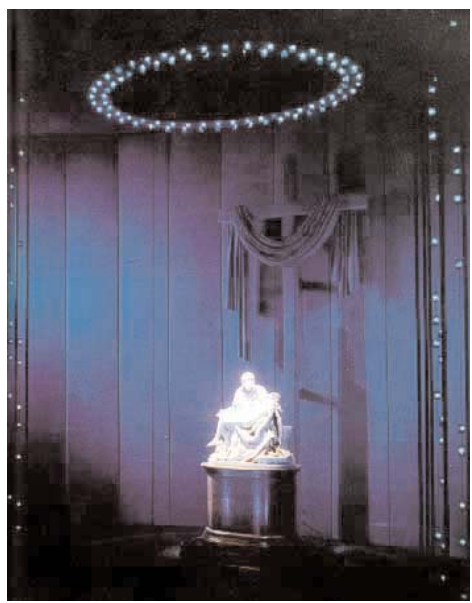

Fig. 09. La Pietà, de Miguel Angel. cionales lograron darle un elevado nivel cultural ${ }^{10}$. Entre ellas - y de modo singular- la del Vaticano. Fue también la exposición donde el pabellón español, obra de Javier Carvajal, fue reconocido y galardonado por el American Institute of Architectes, junto con los de Dinamarca, New Jersey y la compañía IBM.

Sufragado por las parroquias estadounidenses, el proyecto del pabellón vaticano fue fruto de la colaboración de tres firmas de arquitectura: York \& Sawyer, Hurley \& Hughes y Luders \& Associates, quienes concibieron una obra de planta elíptica que figuraba un desarrollo helicoidal convergente en un espacio circular, núcleo y emblema del pabellón, expresado al exterior mediante un cimborrio formado por costillas alzadas al cielo (Fig. 06-08). Comenzado a construir en otoño de 1961, fue el propio Juan XXIII quien puso la primera piedra desde el Vaticano mediante un mando a distancia ${ }^{11}$.

El 4 de octubre de 1965 el pabellón acogió la visita de Pablo VI, en el transcurso de un viaje donde el papa visitó la Exposición, se dirigió a la Asamblea de la ONU y celebró misa en el Yankee Stadium, uniendo los deseos universales de paz con el hecho religioso, mostrando así los «signos de los tiempos».

La principal atracción del pabellón —y de toda la Exposición- fue la «Pietà» de Miguel Ángel, traída expresamente de Roma (Fig. 09). Le acompañaban esculturas de las catacumbas, réplicas de la Capilla Sixtina y de la tumba de san Pedro, una colección de monedas vaticanas, etc. Al igual que en París, en la planta superior había una capilla dedicada al Buen Pastor, símbolo de la Santa Sede, que coronaba el pabellón con su linterna y su gran cruz.

\section{LAS EXPOSICIONES POSTERIORES}

Tras Nueva York, fueron Montreal (Canadá, 1967) y Osaka (Japón, 1970) las ciudades organizadoras de las sucesivas exposiciones, en unas décadas en que se multiplicaron las muestras especializadas, todas ellas fuera de Europa y algunas de gran resonancia: Okinawa (Japón, 1975), Knoxville (Tennessee, EEUU, 1982), Tsukuba (Japón, 1985), Vancouver (Canadá, 1986), etc. Las distancias físicas y culturales y las dificultades financieras impidieron — pese al intento de los católicos de los países respectivos - la presencia vaticana, limitada a emisiones filatélicas conmemorativas ${ }^{12}$.

Sin embargo, la fuerte voluntad de Juan Pablo II buscó allanar los obstáculos, logrando la participación de la Santa Sede — si no en todas, sí en muchas de ellas- allí donde el lugar era más receptivo y la colaboración económica más fácil. Así ocurrió en New Orleans (Louisiana, EEUU, 1984), Brisbane (Australia, 1988) o más tarde en Hannover (Alemania, 2000) (Fig. 10-11) y, en todo caso, en las exposiciones desarrolla- 


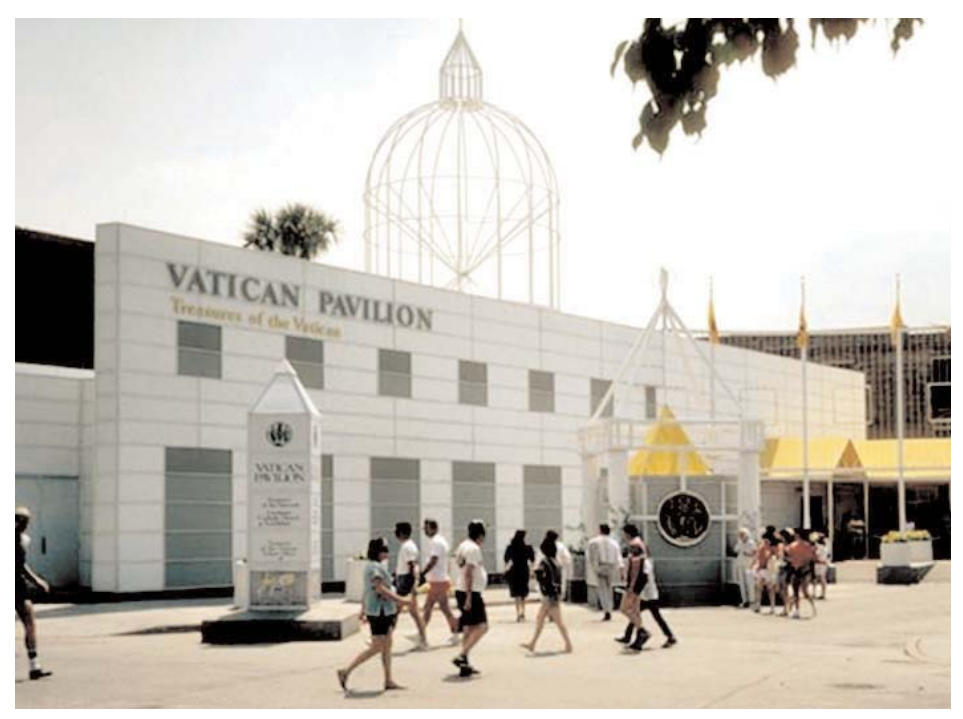

Fig. 10. Nathaniel Curtis, pabellón de la Santa Sede en la Exposición de New Orleans, 1984. Fig. 11. Colin Morris Associates, pabellón de la Santa Sede en la Exposición de Hannover, 2000 (en la otra página).

das en la península Ibérica: Sevilla (1992), Lisboa (1998) y Zaragoza (2008).

La presencia de la Santa Sede fue diversa: a veces quedó reducida a un «stand» en algún pabellón colectivo, mientras que otras veces contó con pabellón propio. En ocasiones - fuera ya de nuestro tema - su presencia sería más bien museística, como en las exhibiciones de los llamados «Tesoros del Vaticano» ${ }^{13}$, realizadas por esos años en Estados Unidos (Metropolitan Museum, Nueva York, 1982) o Japón (1989).

Así, New Orleans y Brisbane pudieron contar con la presencia de la Santa Sede costeada, como en Nueva York, con aportaciones parroquiales. Un importante estudio de Louisiana —el de Nathaniel Curtis—, proyectó el pabellón, alhajado con una significativa muestra artística procedente de los museos vaticanos, de modo similar a como se haría luego en Brisbane.

Unos años más tarde tuvo lugar en Hannover la primera Exposición del tercer milenio, coincidente con el Gran Jubileo del año 2000. El Vaticano presentó en ella un pabellón cuyo proyecto fue fruto de un concurso restringido, siendo elegido Morris Associates, estudio londinense especializado en exposiciones museísticas14. Modesto y convencional —como casi toda la Exposición- desde el inicio se quiso que el pabellón pudiese ser reutilizado como centro eclesial, por lo que el proyecto se concibió teniendo presente su uso definitivo.
Su forma circular evidenciaba el núcleo central y su fuerza de irradiación hacia el exterior, en este caso hacia las cinco secciones temáticas de la exposición, que se complementaban con esculturas vaticanas. La transparencia interna del pabellón intercomunicaba todas las partes.

\section{LAS EXPOSICIONES PENINSULARES: SEVILLA, LISBOA, ZARAGOZA}

Con Juan Pablo II y Benedicto XVI la presencia vaticana se hizo especial en los pabellones ibéricos en Sevilla (1992), Lisboa (1998) y Zaragoza (2008).

Sevilla quiso conmemorar la Era de los Descubrimientos, a los quinientos años del encuentro con el Nuevo Mundo. En ella participaron los mejores arquitectos españoles, encabezados por Julio Cano Lasso, autor del Pabellón de España ${ }^{15}$.

Situado junto al resto de los pabellones de los países europeos, el Pabellón Vaticano quiso ser una síntesis artística de la evangelización americana. El recorrido se articulaba en catorce unidades temáticas que presentaban la llamada «Implantación de la Iglesia» hasta la actualidad, cuando América se ha convertido en el continente de la esperanza y alberga la mitad de los católicos mundiales.

Edificio de propósito moderno y resultado ambiguo, proyectado por Miguel Oriol e Ibarra ${ }^{16}$ (1933), el pabellón era un volumen prismático cubierto por bóve- 


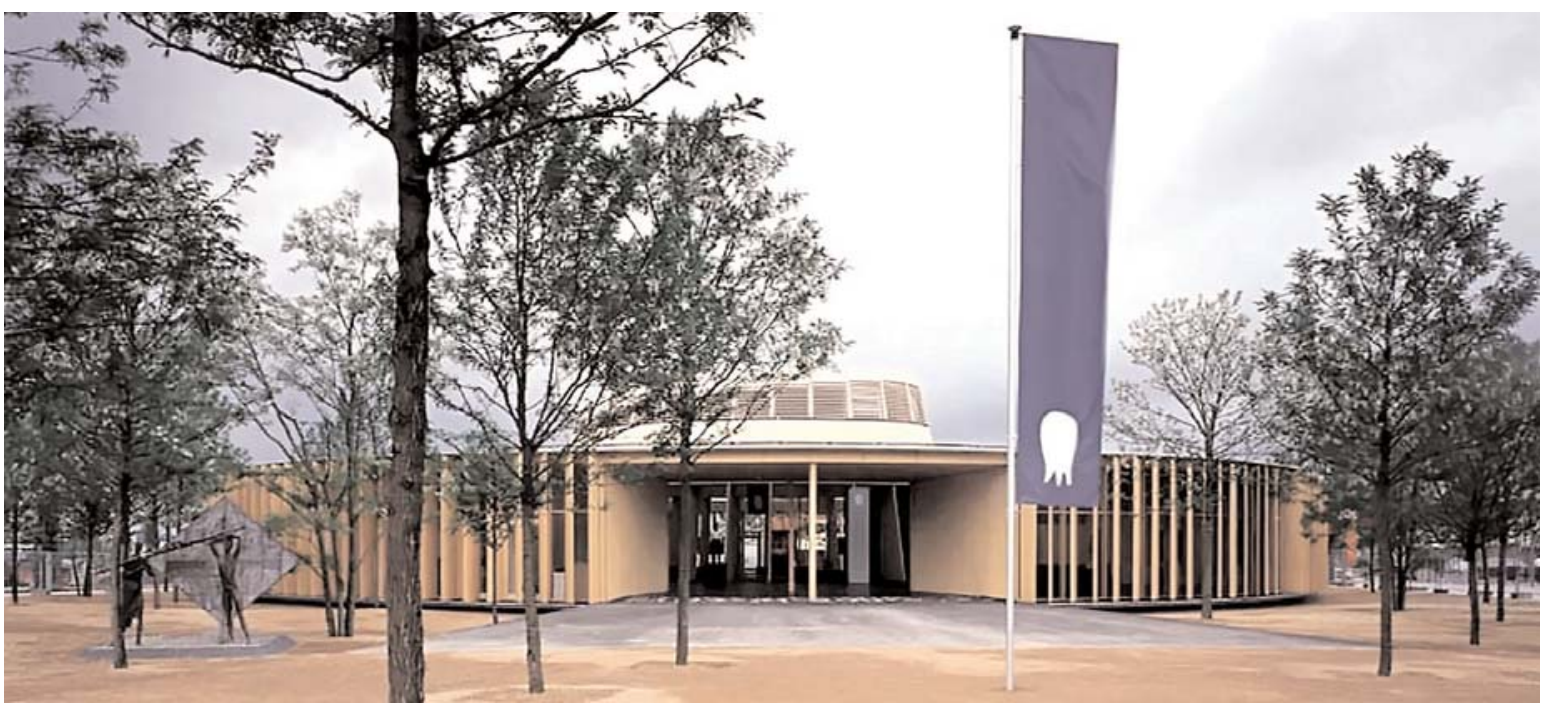

das de reminiscencias eclesiales que se construyó íntegramente en Barcelona con estructura prefabricada de acero y recubrimiento de vidrio (Fig. 12). Las tres plantas del edificio dejaban un gran patio interior, en cuyo centro se colocó la gran custodia de la catedral de Toledo. Conservado hasta 2008, el pabellón fue destruido entonces para construir un complejo de oficinas.

A Sevilla seguirían pocos años después Lisboa (1998) y Zaragoza (2008), si bien en ambos casos la presencia vaticana hubo de limitarse tan sólo a un «stand» dentro del pabellón general o «Parque de las Naciones». En uno y otro caso, la Santa Sede - como tantos otros países - renunció a levantar pabellón propio, prefiriendo agruparse en pabellones internacionales organizados según criterios geográficos o culturales. Estos pabellones-contenedor debían mostrar a la vez la unidad del conjunto y la diversidad de sus naciones respectivas. En nuestro caso, la Santa Sede dispuso dichos espacios interiores mostrando obras de arte más o menos relacionadas con la temática de la Exposición.

\section{CONCLUSIÓN}

Al comienzo del nuevo siglo, es ya una tradición consolidada la presencia vaticana en las exposiciones internacionales. «La Santa Sede — se dijo a propósito de la exposición de Hannover 2000 — desea estar presente como signo de aprecio por la expresión que una exposición universal da a los resultados de la búsqueda científica y el desarrollo técnico, frutos de espíritu humano, para que no falte, en tan cualificado contexto internacional, la palabra del mensaje evangélico» ${ }^{17}$.

Debemos concluir, pues, con una última presencia — este mismo año 2013 - en la Bienal de Arte de Venecia. Presentado por primera vez en la historia de la Bienal, con este pabellón termina hoy la presencia vaticana en las exposiciones internacionales. Frente a una muestra de arte sacro más o menos convencional, se ha ofrecido en él una particular visión del Génesis dirigida a la sociedad laica contemporánea, centrada en tres nodos: la creación, la de-creación y la re-creación, temas a los que Miguel Ángel se enfrentó en la Capilla Sixtina y que han sido reinterpretados por el Studio Azzurro con obras de Tano Festa ${ }^{18}$ (Fig. 13). Sus discutibles resultados quedan en evidencia al contrastarlos con la presencia y la potencia de la creación miguelangelesca.

Como he señalado en una ocasión anterior, «si un espacio sagrado quiere ser verdaderamente de hoy, no tiene más remedio que hablar en el lenguaje de formas que la sociedad de hoy habla (...) pero hablar un lenguaje formal no tiene por qué conllevar el abandono de la tradición en cuanto ésta es composición: orden y memoria, tipología y proyecto» ${ }^{19}$. Pues frente al posible peligro del agotamiento significativo, está el riesgo real de la pérdida de significado. 


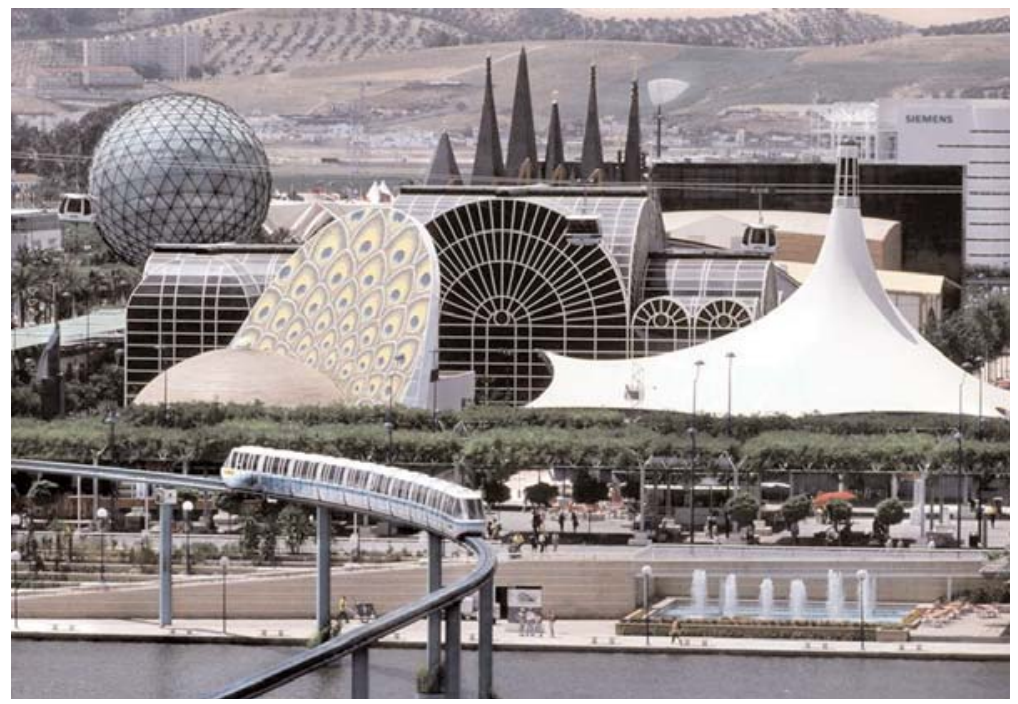

Fig. 12. Miguel Oriol e Ibarra, pabellón de la Santa Sede en la

Exposición de Sevilla, 1992. Fig. 13. Studio Azzurro, pabellón de la Santa Sede en la Bienal de Arte de Venecia, 2013 (en la otra página).

\section{PROCEDENCIA DE LAS ILUSTRACIONES}

Archivo del autor.

\section{NOTAS}

(1) Acerca de los Pactos de Letrán y la Cuestión Romana, vid. mi texto Roma Capital. Invención y construcción de la ciudad moderna (A Coruña: UDC, 2003).

(2) Sobre el pabellón y su significado profético, vid. mi libro Ingleses y españoles. La arquitectura de la Edad de Plata (A Coruña: UDC, 2000), 273-287.

(3) El pabellón aparece citado en la revista parisina L'Illustration (29 de mayo de 1937). Como referencia actual vid. 1937. Exposition internationale des arts et techniques dans la vie moderne, con acceso el 10/10/13, www.expositions-universelles.fr/1937-exposition-internationale-pavillon-pontifical.html.

(4) Cf. Marion Tournon-Branly, Paul Tournon, architecte, 1881-1964 (París: Vincent, 1976); Giorgio Pigafetta y Antonella Mastrorini, Paul Tournon, 1881-1964, le moderniste sage (Bruselas: Mardaga, 2004).

(5) Tras la demolición del pabellón en noviembre de 1938, la imagen de la Virgen se instaló en St. Honoré de Amiens, obra de Paul Tournon, trasladándose en 1982 a Baillet, al norte de París.

(6) Cf. Álvaro Martínez Novillo, «Las artes plásticas durante la guerra española», Cuenta y Razón 21 (1985). Vid. Asimismo, Gilles Chazal, José María Sert, le Titan à l'oeuvre 1874-1945, catálogo de la exposición (París: Petit Palais, 2012).

(7) Cf. Luigi Gedda, «Il padiglione ‘Civitas Dei’ e la Chiesa all’Esposizione Universale di Bruxelles», Quaderni di Chiesa e Quartiere 4 (1957): sp. Asimismo, sendos artículos en L'Architecture d'aujourd'hui 78 (1958) y el número monográfico de Architectural Review 739 (1958). Las revistas españolas centraron su información en el pabellón español: Revista Nacional de Arquitectura 198 y 200 (1958), y Cuadernos de Arquitectura 32 (1958).

(8) Cf. André Lanotte, Jean-Marie André y Jacques Denis, Roger Bastin, architecte, 1913-1988 (Bruselas: Mardaga, 2001).

(9) Cf. los ocho números de la revista Civitas Dei.

Exposition Universelle et Internationale 1959, editada por el Comisariat Général du Saint-Siège, Bruselas, entre 1955 y 1958; Civitas Dei: Catalogue artistique du Pavillon du Saint-Siège à l'Exposition Universelle et Internationale de Bruxelles (Bruselas: Abbaye de Saint-André, 1958).

(10) Cf. Julie Nicoletta, «Art out of Place. International Art Exhibitions at the New York World's Fair of 1964-1965», Interdisciplinar Arts and Sciences 4 (2010): 499-519.

(11) Official Guide Book. Vatican Pavilion. New York World's Fair 1964-1965 y Vatican Pavilion New York World's Fair. A Chronicle (Nueva York: s/e, 1965). La revista Arquitectura dedicó a la exposición el nº 68 (1964), centrando su información en el pabellón español.

(12) Curiosamente, mientras el Vaticano se limitó a dedicarle una emisión filatélica, la Iglesia de Jesucristo de los Santos de los Ultimos Días (mormones) participó en Osaka con un pabellón propio.

(13) Val A. McInnes, ed., Treasures of the Vatican: New Orleans Vatican Pavilion at the 1984 Louisiana World Exposition (New Orleáns: FAIA, 1984). Desmond Macaully, The Holy See Vatican Collections. The Pavilion of the Holy See at World Expo 1988 (Brisbane: Ist ${ }^{\circ}$ Trust, 1988).

(14) Rossella Mombelli, «Gesù Cristo, ieri, oggi e per l'eternità. Intervista al Nunzio Apostolico, Giovanni Lajolo», Chiesa Oggi. Architettura e Comunicazione 43 (2000), con acceso el 10/10/13, www.dibaio.com/chiesa-oggi/oggetti/redazionale/gesu- 


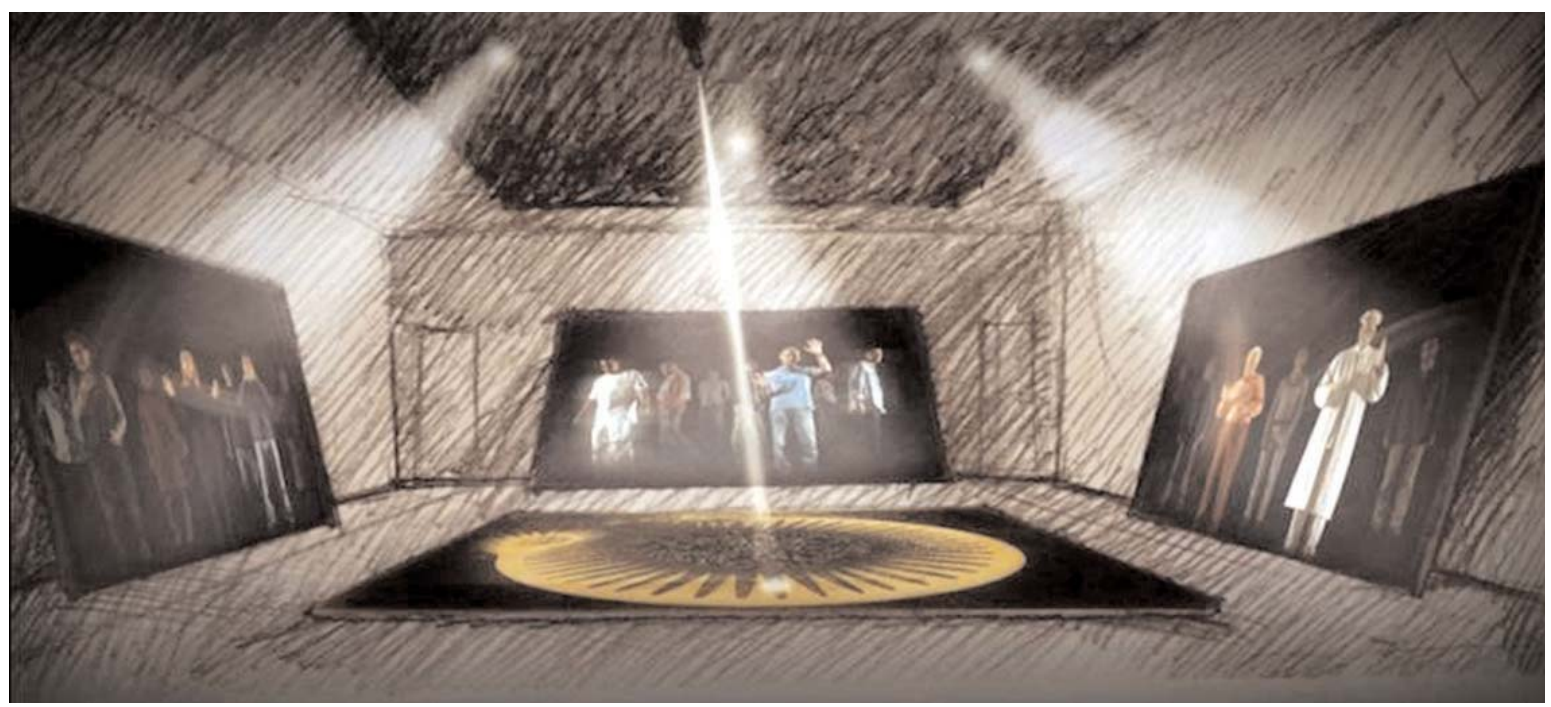

cristo-ieri-oggi-e-per-l-eternita.aspx. Sobre Morris Associates, vid. «Vatican Pavilion», con acceso el 10/10/13, www.exhibitiondesign.com/projects/vatican-pavilion.php. En Hannover hubo un «Pabellón de las religiones cristianas», promovido por el Evangelische Büro, proyecto de gmp Architekten von Gerkan (vid. GMP, «Iglesia Cristiana», Arquitectura Viva 72 (2000): 64-67).

(15) Entre las revistas españolas que dedicaron su atención a la Expo ‘92 destaca $A \& V$ (Madrid), que le dedicó los números monográficos 16 (1988) y 34/35 (1992), aunque sin ninguna referencia especial al Pabellón Vaticano.

(16) Autor de la Universidad de Deusto (San Sebastián) y la madrileña Torre Europa, Oriol era desde 1990 miembro de la
Real Academia de Bellas Artes; en la Expo’92 construyó también el pabellón Cruzcampo. La dirección científica la llevó Paulino Castañeda, director del Departamento de Historia de América de la Universidad de Sevilla.

(17) Mombelli, «Gesù Cristo, ieri, oggi».

(18) Studio Azzurro fue fundado en Milán, en 1982, por Fabio Cirifino, Paolo Rosa y Leonardo Sangiorgi, especialistas en artes visuales, fotografía, gráfica y animación.

(19) José Ramón Alonso Pereira, «Memoria y proyecto en la arquitectura religiosa contemporánea», en Esteban FernándezCobián, ed., Arquitecturas de lo sagrado: memoria y proyecto (A Coruña: Netbiblo, 2009), 367. 